\title{
Imaging of Pancreatic Trauma-A Clinical Scenario-Based Approach
}

\author{
Naren Hemachandran ${ }^{1}$ Shivanand Gamanagatti ${ }^{1}$ \\ ${ }^{1}$ Department of Radiodiagnosis, All India Institute of Medical \\ Sciences, New Delhi, India
}

\begin{abstract}
Address for correspondence Shivanand Gamanagatti, MBBS, MD, Department of Radiodiagnosis, All India Institute of Medical Sciences, 81b, New Delhi 110029, India (e-mail: shiv223@gmail.com).
\end{abstract}

\begin{abstract}
Pancreatic injury, although uncommon in the setting of abdominal trauma, is associated with high morbidity and mortality. While the clinical signs are nonspecific, the imaging signs can be very subtle in the early stages leading to missed injuries that present later as complications. Contrast-enhanced computed tomography (CT) is the main workhorse and initial imaging modality in the setting of abdominal trauma, while magnetic resonance imaging (MRI) with magnetic resonance cholangiopancreatography is used as a problem-solving tool in pancreatic trauma.

This article provides a review of the imaging of pancreatic trauma and has been organized into common clinical scenarios-Suspected pancreatic injury with normal-appearing pancreas on $\mathrm{CT}$; definite pancreatic injury on $\mathrm{CT}$, late presentation or complication in a patient with pancreatic injury. The role of the radiologist in each scenario is described as follows: to identify subtle secondary signs of injury and resort to $\mathrm{MRI}$ or a repeat imaging wherever necessary in a suspected pancreatic injury with normal-appearing pancreas on CT (Scenario 1); to look for primary/hard signs, grade the injury according to American Association of Surgery for Trauma Organ Injury Scale,

Keywords

- pancreatic trauma

- computed tomography

- MRCP

- complications

- angiography

- CT-guided drainage and utilize MRI if necessary to ascertain the presence of ductal injury when a definite pancreatic injury is seen on CT (Scenario 2); and to diagnose various complications and help in the management of complications such as draining collections or vascular complications like pseudoaneurysms (Scenario 3).

Radiologists should be aware of the primary and secondary signs of pancreatic injury so as to enable prompt diagnosis and further management. Radiologists play an important role not only in the diagnosis of pancreatic injuries but also in the management of certain complications.
\end{abstract}

\section{Introduction}

Pancreatic injury is uncommon and is seen in less than $2 \%$ of patients who sustain blunt abdominal trauma. ${ }^{1}$ The clinical signs are nonspecific, and imaging signs are subtle during the initial stages. Even subtle undetected injuries can lead to various complications associated with high morbidity and mortality. ${ }^{2-4}$

Pancreas being a retroperitoneal organ is usually only injured in high force blunt injuries, where it is compressed against the spine due to anteroposterior compressive forces.
This is commonly due to seat-belt or steering wheel injuries in road traffic accidents. It can also be injured in case of high force spinal injuries associated with fall from height. ${ }^{1,5,6}$

Injury to pancreas is usually associated with injuries to the other abdominal organs such as spleen, liver, adrenal, duodenum, mesentery as well as the spine depending on the mode of injury and the point of impact. ${ }^{7.8}$ Only $5 \%$ of the pancreatic injuries are directly related to the fatal outcome. Coexisting injuries with associated fatal hemorrhage are the leading cause of early deaths, while complications such as infections and multiorgan failure cause most late
DOI https://doi.org/ 10.1055/s-0040-1701353 ISSN 2581-9933.
(C)2020 Indian Society of Gastrointestinal and Abdominal Radiology
License terms

()(1) $\Theta$ 
ones. Complications related to pancreatic injury are seen in nearly one-third of the patients who survive the first 48 hours. $^{9-12}$

Computed tomography (CT) is the initial imaging modality in patients with blunt imaging trauma. Magnetic resonance imaging (MRI) with magnetic resonance cholangiopancreatography (MRCP) is used to ascertain ductal injury in a patient with pancreatic injury on the initial CT. Although endoscopic retrograde cholangiopancreatography (ERCP) is considered the gold standard for demonstrating ductal injury, MRI is noninvasive and also enables us to demonstrate the status of the duct upstream of the laceration with better definition of parenchymal injury and the extent and location of peripancreatic fluid collections.

In this article, we describe the imaging signs and role of radiologist in commonly encountered clinical scenarios in relation to pancreatic trauma. Three such scenarios are described-Suspected pancreatic injury with normal-appearing pancreas on $\mathrm{CT}$, definite pancreatic injury on $\mathrm{CT}$, late presentation or complication in a patient with pancreatic injury.
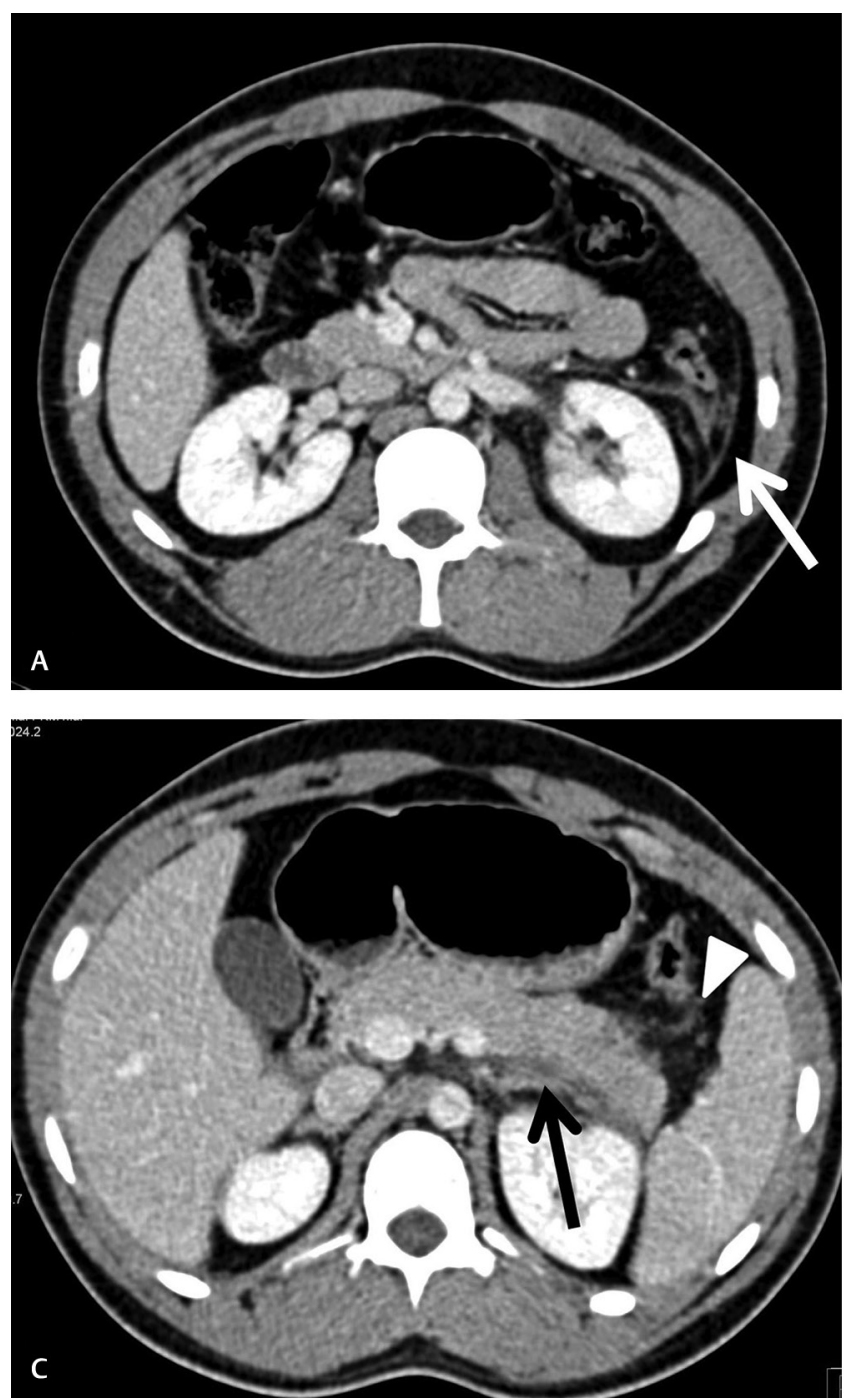

\section{Scenario 1-Suspected Pancreatic Injury with} Normal-Appearing Pancreas on Initial CT

A normal-appearing pancreas can be seen in 20 to $40 \%$ of patients with acute blunt pancreatic injuries, especially when imaging is done within the first 12 hour after injury. This could be due to various factors:

1. Timing of the scan-pancreatic injury evolves over time. The radiological findings become more apparent with time due to development of post-traumatic pancreatitis, edema, leakage of pancreatic enzymes, and subsequent auto-digestion of the surrounding parenchyma.

2. Adipose tissue-lesser fat surrounding the pancreas in thin patients and in children decreases the conspicuity of the radiological findings.

3. Other factors-like obscuration of the fracture plane, hemorrhage, and close apposition of the pancreatic fragments.

There are no clinical features or laboratory parameters (including serum amylase levels) that are specific for pancreatic injury. ${ }^{13,14}$ In such patients, the radiologists have to
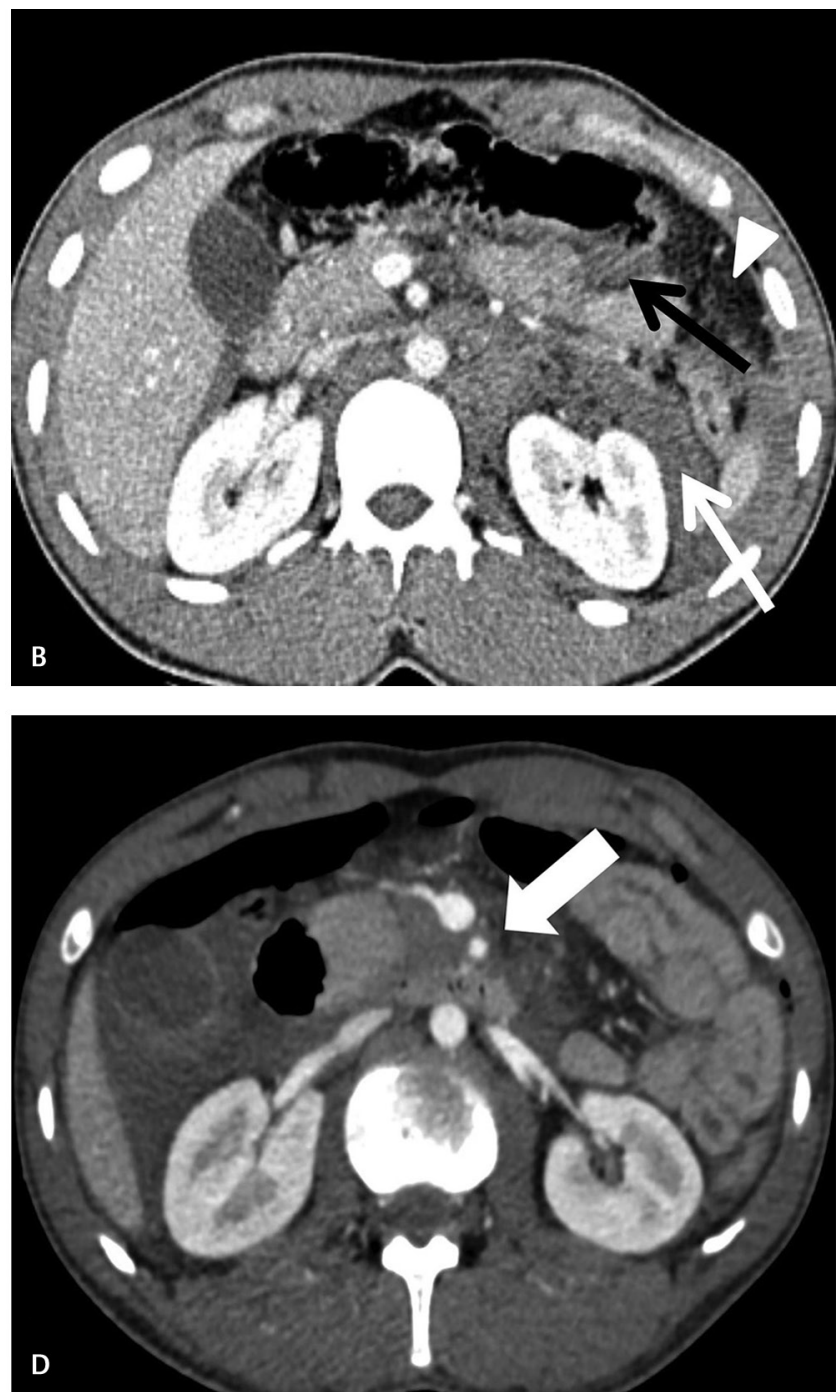

Fig. 1 Secondary signs of pancreatic injury in axial contrast-enhanced computed tomography of four different patients (A-D) showing fluid and thickening of the anterior renal fascia (white arrow), fat stranding in the transverse mesocolon (solid arrowhead), peripancreatic fluid (black arrow), fluid around the superior mesenteric artery (solid arrow). 
depend on various secondary signs that are seen associated with pancreatic injuries. The presence of the secondary signs should raise the possibility of pancreatic injury ( - Fig. $\mathbf{1}$ ). Such patients can be followed up with repeat imaging.

Secondary signs seen in patients with pancreatic injuries are as follows:

1. Fat stranding in peripancreatic fat and mesentery

2. Fluid surrounding the superior mesenteric artery

3. Thickening of the left anterior renal fascia

4. Peripancreatic fluid collection

5. Fluid in the anterior and posterior pararenal spaces

6. Fluid in transverse mesocolon and lesser sac

7. Extraperitoneal or intraperitoneal fluid without associated other solid organ injury

Repeat imaging is done in such patients after 48 to 72 hours to look for definitive signs of pancreatic injury. ${ }^{6,15,16}$ Due to the higher contrast resolution, subtle contusions or lacerations not seen on initial CT may be seen on MRI ( - Fig. 2).
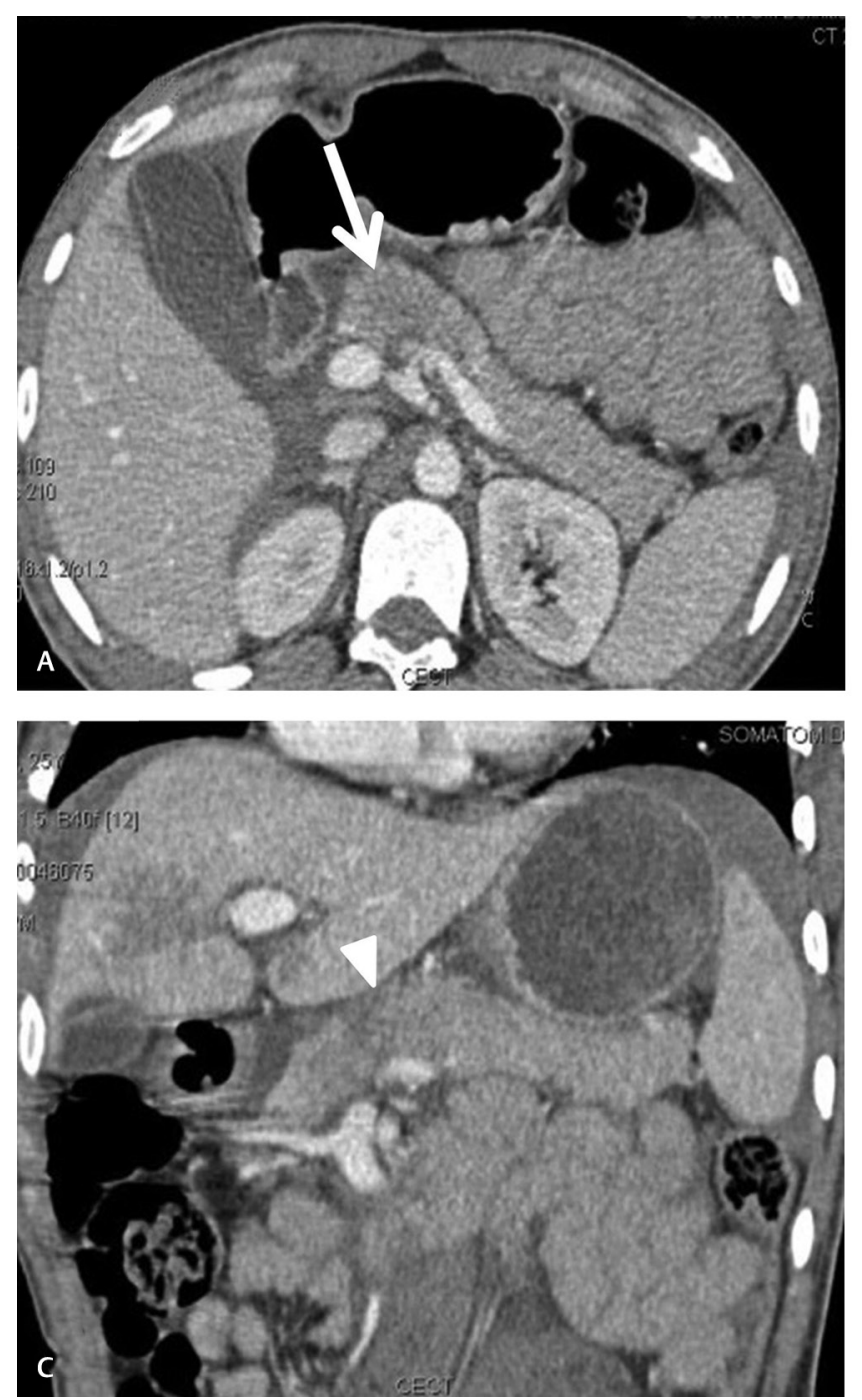

\section{Scenario 2-Definitive Injury on Initial CT}

There are various signs ( $\mathbf{- F i g}$. $\mathbf{3 A}$ and $\mathbf{B}$ ) that may be seen on $\mathrm{CT}$, which are considered as "Hard signs" of pancreatic injury. ${ }^{6,15,16}$ These include:

1. Fracture of the pancreas

2. Pancreatic laceration

3. Focal or diffuse pancreatic enlargement/edema

4. Pancreatic hematoma

5. Active bleeding/extravasation of intravenous contrast

6. Fluid separating the splenic vein from posterior aspect of pancreas

CT characteristics-Pancreatic contusion appears as focal or diffuse area of low or heterogeneous attenuation within the normally enhancing parenchyma. While involvement of less than one anatomical division of pancreas (head, neck, body, or tail) is considered as minor contusion, involvement of more than one anatomical division is considered a major contusion. ${ }^{16}$
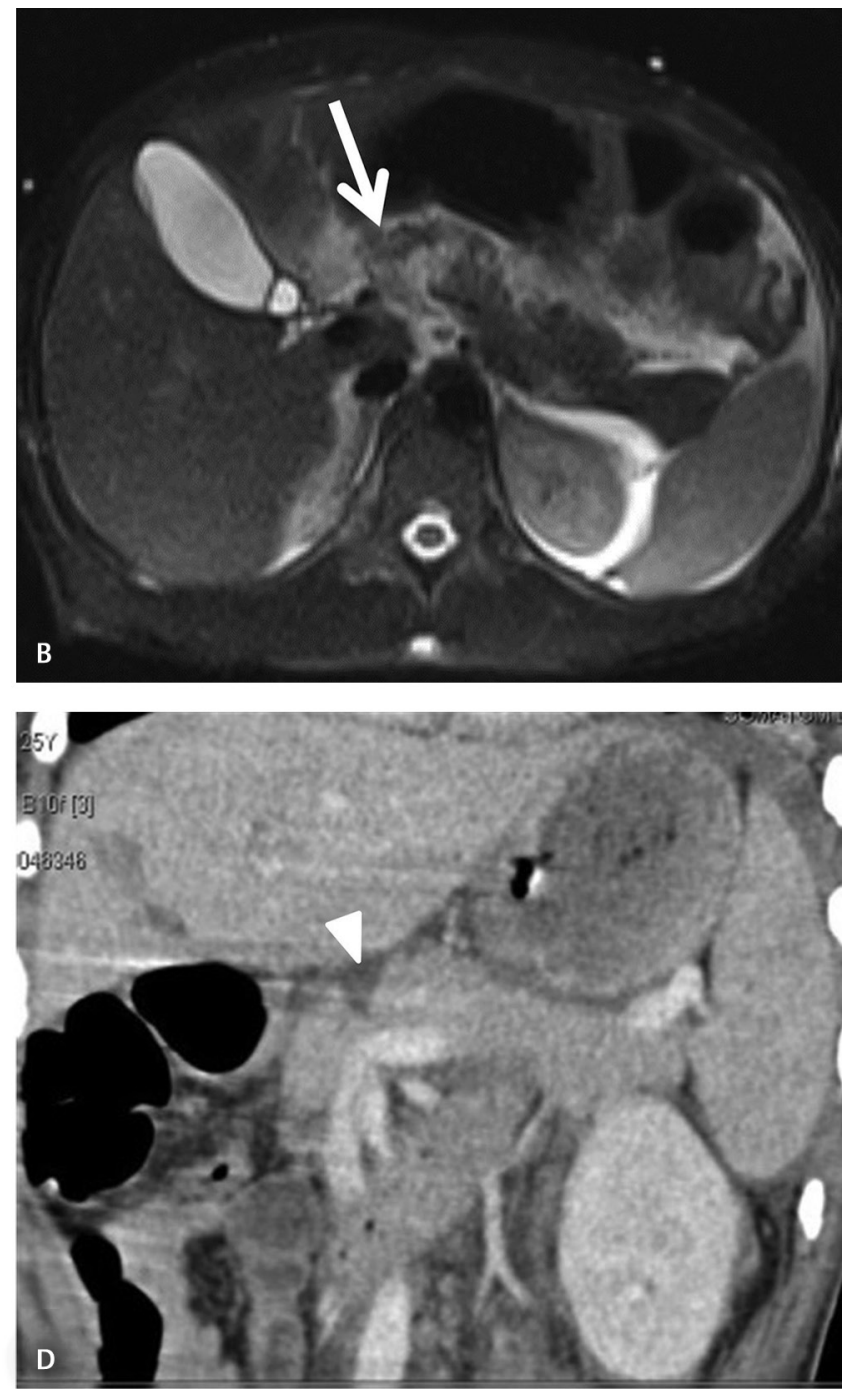

Fig. 2 Role of magnetic resonance (MR) and delayed imaging in case of subtle findings. Patient 1-Axial contrast computed tomography (CT) (A) and axial T2-weighted image (B) at the level of the pancreas showing subtle contusion (white arrow) in the body of the pancreas that is better visualized on the MR (B) done within 24 hours of the CT (A). Patient 2-Coronal contrast enhanced CT done immediately after the trauma (C) and after 48 hours follow-up (D) showing subtle superficial laceration with surrounding contusion (solid arrowhead) in the body of the pancreas that is better delineated in the follow-up scan. 

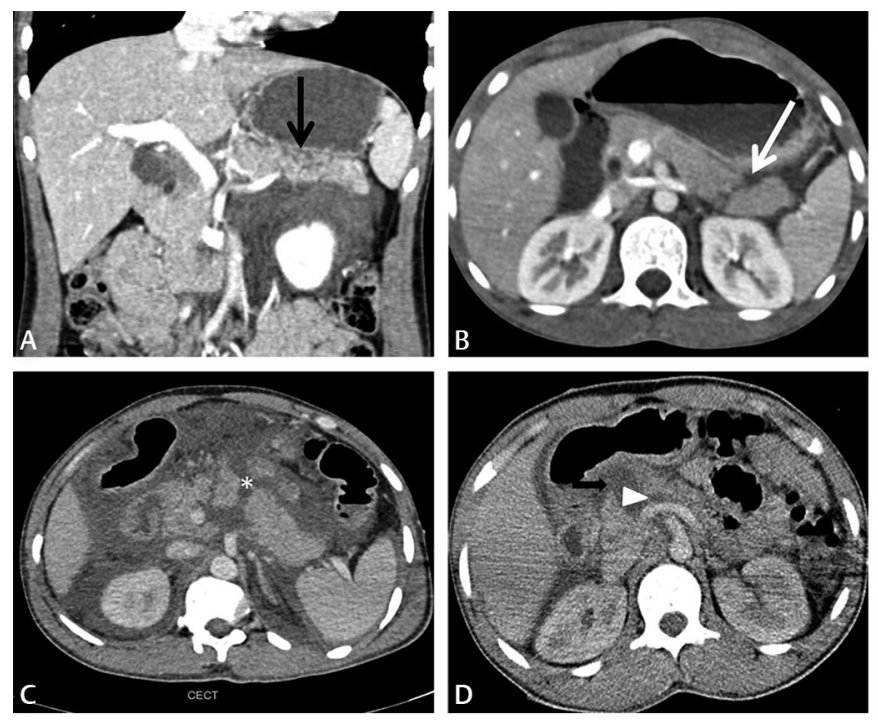

A
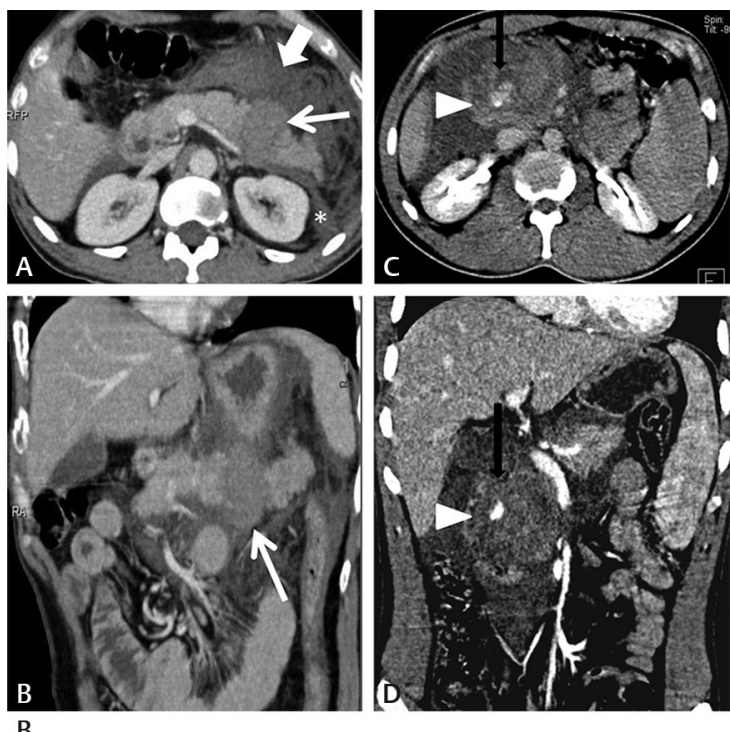

Fig. 3 (A) Definite computed tomography (CT) signs of pancreatic injury-Lacerations (A) Subtle superficial lacerations (black arrow) involving less than $50 \%$ of the gland thickness (American Association for Surgery in Trauma [AAST] grade 1). (B) Full-thickness laceration (transection or fracture) (white arrow) involving the distal body (AAST grade 3). (C and D) Proximal transection (AAST grade 4) with two definite fracture lines in $\mathbf{C}$ (asterisk) and fluid between the pancreas and the splenic vein in $\mathbf{D}$ (solid arrowhead). (B) Definite CT signs of pancreatic injury. Patient 1-Axial (A) and coronal (B) contrast-enhanced CT showing a focal area of intraparenchymal hematoma (white arrow) mildly hyperdense to the paravertebral muscles in the tail of the pancreas corresponding to a AAST grade 3 injury with fat stranding in the transverse mesocolon (solid arrow), fluid, and thickening of the left anterior renal fascia (asterisk). Patient 2-Axial (C) and coronal (D) contrast-enhanced CT showing AAST grade 5 injury with massive pancreatic head disruption (arrow head) and active extravasation of contrast (black arrow).

Lacerations appear as a low-attenuation line usually oriented perpendicular to the long axis of the pancreas. This low attenuation line is due to the separation of fragments with fluid or blood. As discussed earlier, these findings may not be conspicuous in the early stage. Also in a patient with secondary signs, a laceration should be carefully looked for as it may be seen on only one or two sections. In some patients, a pancreatic cleft can be identified, usually between the neck and body of the pancreas. Pancreatic lacerations should be differentiated from clefts. The presence of secondary signs along with surrounding fat stranding favors laceration, while a cleft is lined by fat with clear surrounding area. ${ }^{17}$

Lacerations can either be superficial or deep. There is involvement of less than half of the thickness of the gland in superficial lacerations and are usually not associated with involvement of the main pancreatic duct. Deep lacerations involve more than half of the thickness of the gland and are associated with higher chances of duct disruption. This $50 \%$ depth of laceration is used as a substitute marker for ductal involvement as it may not always be possible to trace the non-dilated pancreatic duct on CT. A fracture or transection is a full thickness laceration involving the entire thickness of gland and is most commonly seen in the body or neck of the gland. ${ }^{18}$

Pancreatic hematoma appears as an ill-defined area of hyper-attenuation within the substance of the gland and is considered a very specific sign of pancreatic trauma. Similarly, active contrast extravasation within the gland that appears as extraluminal contrast leak, which disperses on a delayed scan, is also specific for pancreatic injury. ${ }^{19}$

MRI characteristics-MRI is usually used as a problem-solving tool in pancreatic trauma. In our institution, MRI is performed in case of equivocal CT findings or to evaluate the pancreatic duct if conservative management is planned. Pancreatic contusions usually appear as ill-defined focal T2 hyperintense areas, while lacerations appear as linear T2 hyperintense areas. The extension of the lacerations to directly involve the pancreatic duct can be better appreciated on MRI. Pancreatic hematoma appears as T1 hyperintense areas within the gland with variable signal intensity on T2-weighted images. ${ }^{19,20}$

Duct transections and ductal involvement by lacerations are best seen on MRCP images. MRI also demonstrates the duct distal to the site of injury and also the presence of peripancreatic fluid collections and the presence of any communication of such collections with the pancreatic duct.

\section{AAST Grading and Management Options}

Moore et al on behalf of the American Association of Surgery for Trauma (AAST) had proposed the Organ Injury Scale (OIS) grading of pancreatic trauma in $1990 .{ }^{21}$ This is a surgical grading with CT correlates for each grade ( - Fig. 4 ). This grading system is widely used and has enabled uniform reporting, easy understanding of the radiological findings by the surgeon and has management implications (-Table $\mathbf{1}$ ).

\section{Scenario 3-Late Presentation or Complications}

Pancreatic injuries without associated ductal injury usually resolve with nonoperative management without significant complications, and treatment is guided by the clinical course. Pancreas-related complications occur in 11 to $62 \%$ of patients with an associated average morbidity rate of $36 \%{ }^{22}$ The grade 

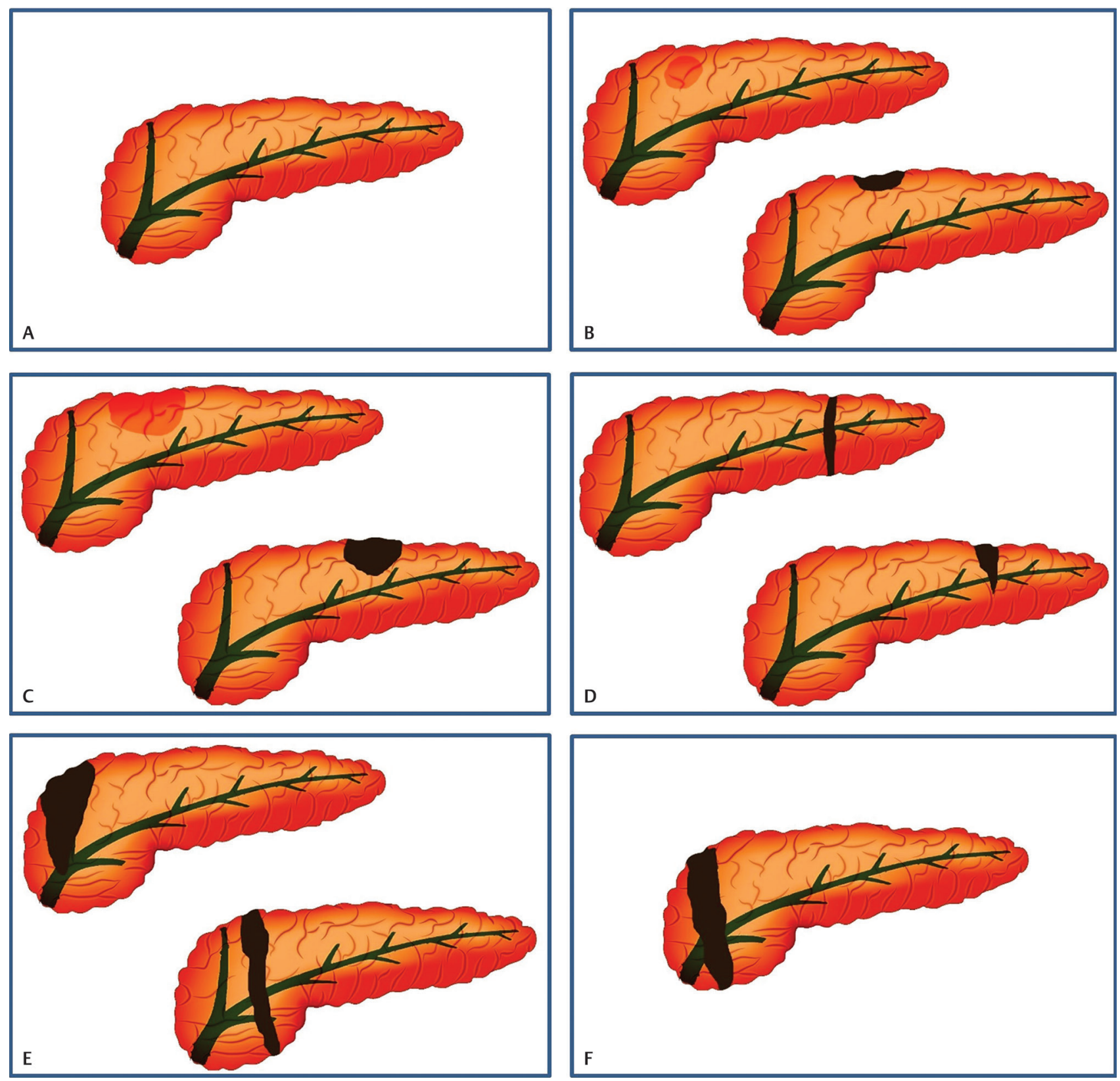

Fig. 4 Graphical illustration of the American Association for Surgery in Trauma grading for pancreatic trauma. A (normal), B (grade 1), C (grade 2), D (grade 3), $\mathbf{E}$ (grade 4), and $\mathbf{F}$ (grade 5). Hematoma depicted in orange and lacerations in brown. Detailed descriptions for various grades given in $\mathbf{\sim}$ Table $\mathbf{1}$.

Table 1 AAST Organ Injury Scale (OIS) for pancreatic trauma with appropriate management options

\begin{tabular}{|l|l|l|}
\hline $\begin{array}{l}\text { Grade of injury } \\
\text { (OIS) }\end{array}$ & Description & Management options \\
\hline Grade I & $\begin{array}{l}\text { Hematoma: Minor contusion without duct injury } \\
\text { Laceration: Superficial laceration without duct injury }\end{array}$ & $\begin{array}{l}\text { Observation/conservative management } \\
\text { Simple external drainage } \\
\text { Omental pancreatography and drainage }\end{array}$ \\
\hline Grade II & $\begin{array}{l}\text { Hematoma: Major contusion without duct injury or tissue loss } \\
\text { Laceration: Major laceration without duct injury or tissue loss }\end{array}$ & $\begin{array}{l}\text { Distal pancreatectomy +/- splenectomy; } \\
\text { Roux-en-Y distal pancreatojejunostomy }\end{array}$ \\
\hline Grade III & $\begin{array}{l}\text { Laceration: Distal transection or parenchymal injury with duct injury } \\
\text { Grade IV }\end{array}$ & $\begin{array}{l}\text { Drainage in damage control situations } \\
\text { Whipple procedure } \\
\text { Distal or anterior Roux-en-Y pancreatojeju- } \\
\text { nostomy } \\
\text { Endoscopically placed stent }\end{array}$ \\
\hline Grade V & Laceration: Massive disruption of pancreatic head & $\begin{array}{l}\text { Pancreatoduodenectomy } \\
\text { Drainage in damage control situations }\end{array}$ \\
\hline
\end{tabular}


of injury, delay in diagnosis, and associated organ injuries are factors that impact the outcome. Various complications include pancreatic fistula, traumatic pancreatitis, pseudocyst formation, infected pancreatic collections, and major duct stricture formation ( - Fig. 5). Other less frequent complications are peritonitis, intestinal obstruction, gastrointestinal bleeding, and acalculous cholecystitis. More severe complications include septicemia and multiorgan dysfunction leading to death.,8

Most common complication is pancreatic fistula formation. ${ }^{16,23}$ CT-guided drainage of fistula or the associated collection over weeks is the treatment of choice. ERCP to delineate the fistulous anatomy followed by surgery or endoscopic stenting is done in cases of persistently high output drainage or internal communication with a hollow viscus or pleural cavity. Stenting or Roux-en-Y procedures are usually used for proximal fistulas, while distal fistulas are treated by pancreatectomy.

Pancreatic pseudocysts are usually seen after missed injuries to distal pancreas or as a sequela of nonoperative management. MRCP is done to look for ductal communication.
The presence of a communication warrants an endoscopic stenting along with percutaneous or endoscopic drainage of the pseudocyst, while only drainage would suffice if no direct ductal communication is evident. Surgical or endoscopic cystogastrostomy or cystoenterostomy is considered if the pseudocyst is abutting the posterior wall of the stomach or bowel walls. ${ }^{24,25}$

The erosive nature of the pancreatic enzymes leads to the formation of pseudoaneurysms of vessels in the vicinity of the pancreas including the splenic, gastroduodenal, common hepatic, and left gastric arteries. ${ }^{26-28}$ Pseudoaneurysms are potentially life threatening and their rupture can lead to extensive blood loss and internal bleeding. They may present clinically as blood in the drain or hematemesis or melena or hemobilia. They are usually diagnosed with CT angiography in a hemodynamically stable patient. CT angiography not only helps in localizing the site of pseudoaneurysm but also acts as a roadmap for angiography and aids in planning for embolization. Coils or glue are the agents usually used for embolization depending on the location and size of the pseudoaneurysm. ${ }^{28}$
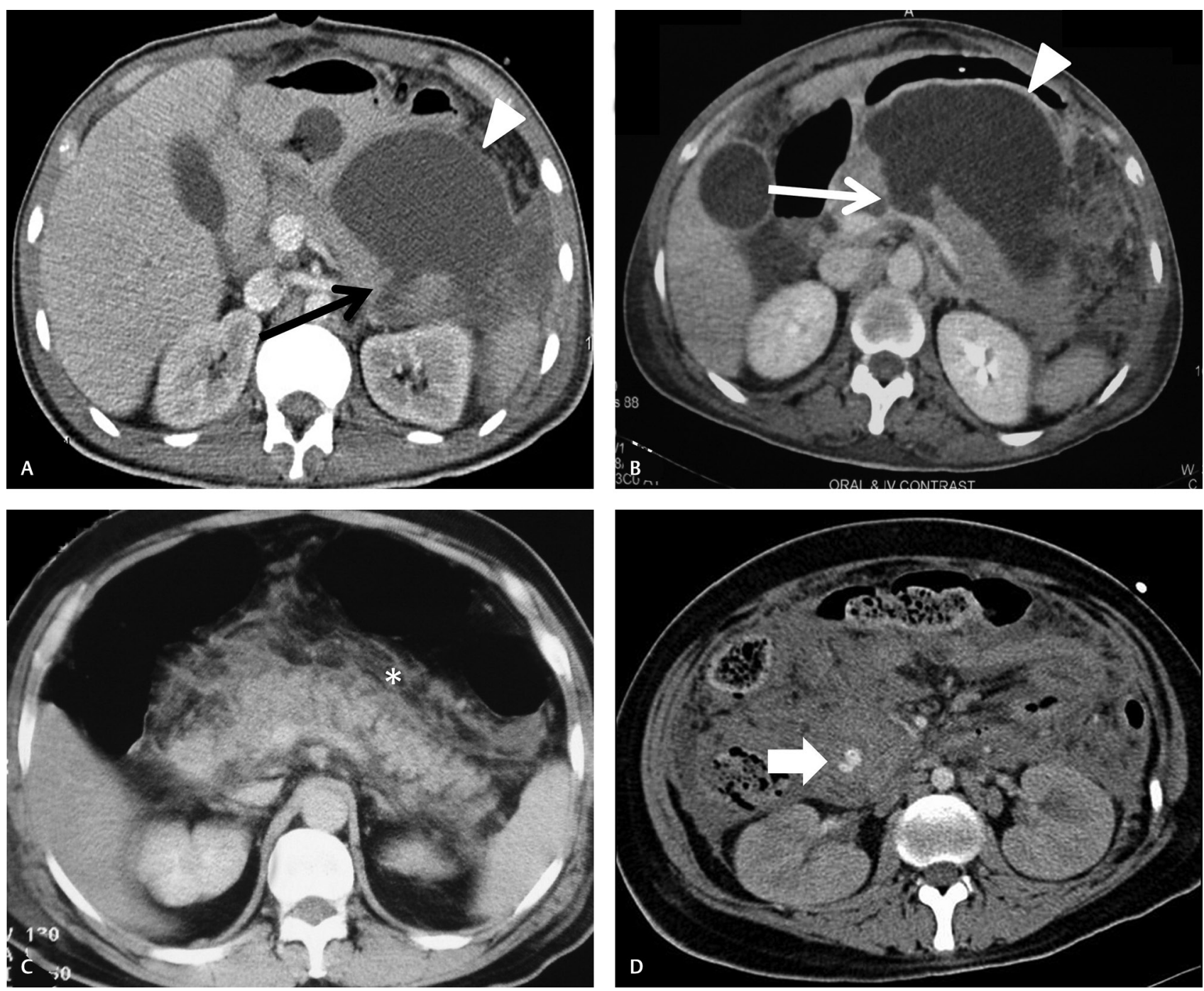

Fig. 5 Complications of pancreatic injury in four different patients. Pseudocyst formation (solid arrowhead) with distal (A, black arrow) and proximal (B, white arrow) transection. Traumatic pancreatitis $(\mathbf{C})$ with diffusely bulky pancreas with surrounding fat stranding (asterisk). Pseudoaneurysm formation in relation to the gastroduodenal artery (D, solid arrow) with surrounding hematoma. 
Pancreatic duct strictures may occur as sequelae of nonoperative management due to the development of fibrosis at the site of injury. Chronic obstruction leads to raised intraductal pressure causing chronic obstructive pancreatitis, which may present months to years after the initial trauma.

In conclusion, pancreatic injuries are rare but are associated with significant complications and morbidity. CT is the commonly used modality with MRI being used as a problem-solving tool, especially to diagnose ductal injuries. Radiologists should be aware of the primary and secondary signs of pancreatic injury so as to enable prompt diagnosis and further management. Radiologists play an important role not only in the diagnosis of pancreatic injuries but also in the management of various complications with CT-guided drainage and angiographic embolization whenever necessary.

\section{Conflict of Interest}

None declared.

\section{References}

1 Cirillo RL Jr, Koniaris LG. Detecting blunt pancreatic injuries. J Gastrointest Surg 2002;6(4):587-598

2 Bigattini D, Boverie JH, Dondelinger RF. CT of blunt trauma of the pancreas in adults. Eur Radiol 1999;9(2):244-249

3 Kao LS, Bulger EM, Parks DL, Byrd GF, Jurkovich GJ. Predictors of morbidity after traumatic pancreatic injury. J Trauma 2003;55(5):898-905

4 Leppäniemi AK, Haapiainen RK. Risk factors of delayed diagnosis of pancreatic trauma. Eur J Surg 1999;165(12):1134-1137

5 Arkovitz MS, Johnson N, Garcia VF. Pancreatic trauma in children: mechanisms of injury. J Trauma 1997;42(1):49-53

6 Daly KP, Ho CP, Persson DL, Gay SB. Traumatic retroperitoneal injuries: review of multidetector CT findings. Radiographics 2008;28(6):1571-1590

7 Madiba TE, Mokoena TR. Favourable prognosis after surgical drainage of gunshot, stab or blunt trauma of the pancreas. $\mathrm{Br} \mathrm{J}$ Surg 1995;82(9):1236-1239

8 Bradley EL III, Young PR Jr, Chang MC, et al. Diagnosis and initial management of blunt pancreatic trauma: guidelines from a multiinstitutional review. Ann Surg 1998;227(6):861-869

9 Jones RC. Management of pancreatic trauma. Am J Surg 1985;150(6):698-704

10 Asensio JA, Demetriades D, Hanpeter DE, Gambaro E, Chahwan S. Management of pancreatic injuries. Curr Probl Surg 1999;36(5):325-419

11 Sims EH, Mandal AK, Schlater T, Fleming AW, Lou MA. Factors affecting outcome in pancreatic trauma. J Trauma 1984;24(2):125-128

12 Patton JH Jr, Lyden SP, Croce MA, et al. Pancreatic trauma: a simplified management guideline. J Trauma 1997;43(2):234-239, discussion 239-241
13 Adamson WT, Hebra A, Thomas PB, Wagstaff P, Tagge EP, Othersen HB. Serum amylase and lipase alone are not cost-effective screening methods for pediatric pancreatic trauma. J Pediatr Surg 2003;38(3):354-357, discussion 354-357

14 Chrysos E, Athanasakis E, Xynos E. Pancreatic trauma in the adult: current knowledge in diagnosis and management. Pancreatology 2002;2(4):365-378

15 Linsenmaier U, Wirth S, Reiser M, Körner M. Diagnosis and classification of pancreatic and duodenal injuries in emergency radiology. Radiographics 2008;28(6):1591-1602

16 Gupta A, Stuhlfaut JW, Fleming KW, Lucey BC, Soto JA. Blunt trauma of the pancreas and biliary tract: a multimodality imaging approach to diagnosis. Radiographics 2004;24(5):1381-1395

17 Dodds WJ, Taylor AJ, Erickson SJ, Lawson TL. Traumatic fracture of the pancreas: CT characteristics. J Comput Assist Tomogr 1990;14(3):375-378

18 Kumar A, Panda A, Gamanagatti S. Blunt pancreatic trauma: a persistent diagnostic conundrum? World J Radiol 2016;8(2):159-173

19 Nirula R, Velmahos GC, Demetriades D. Magnetic resonance cholangiopancreatography in pancreatic trauma: a new diagnostic modality? J Trauma 1999;47(3):585-587

20 Panda A, Kumar A, Gamanagatti S, et al. Evaluation of diagnostic utility of multidetector computed tomography and magnetic resonance imaging in blunt pancreatic trauma: a prospective study. Acta Radiol 2015;56(4):387-396

21 Moore EE, Cogbill TH, Malangoni MA, et al. Organ injury scaling, II: pancreas, duodenum, small bowel, colon, and rectum. J Trauma 1990;30(11):1427-1429

22 Meredith JW, Trunkey DD. CT scanning in acute abdominal injuries. Surg Clin North Am 1988;68(2):255-268

23 Ilahi O, Bochicchio GV, Scalea TM. Efficacy of computed tomography in the diagnosis of pancreatic injury in adult blunt trauma patients: a single-institutional study. Am Surg 2002;68(8):704-707, discussion 707-708

24 Lin B-C, Fang J-F, Wong Y-C, Liu N-J. Blunt pancreatic trauma and pseudocyst: management of major pancreatic duct injury. Injury 2007;38(5):588-593

25 Akhrass R, Yaffe MB, Brandt CP, Reigle M, Fallon WFJr, Malangoni MA. Pancreatic trauma: a ten-year multi-institutional experience. Am Surg 1997;63(7):598-604

26 De Rosa A, Gomez D, Pollock JG, et al. The radiological management of pseudoaneurysms complicating pancreatitis. JOP 2012;13(6):660-666

27 Otah E, Cushin BJ, Rozenblit GN, Neff R, Otah KE, Cooperman AM. Visceral artery pseudoaneurysms following pancreatoduodenectomy. Arch Surg 2002;137(1):55-59

28 Pang TC, Maher R, Gananadha S, Hugh TJ, Samra JS. Peripancreatic pseudoaneurysms: a management-based classification system. Surg Endosc 2014;28(7):2027-2038 